\title{
Epigenetics and transgenerational inheritance in domesticated farm animals
}

\author{
Amanda Feeney, Eric Nilsson and Michael K Skinner ${ }^{*}$
}

\begin{abstract}
Epigenetics provides a molecular mechanism of inheritance that is not solely dependent on DNA sequence and that can account for non-Mendelian inheritance patterns. Epigenetic changes underlie many normal developmental processes, and can lead to disease development as well. While epigenetic effects have been studied in well-characterized rodent models, less research has been done using agriculturally important domestic animal species. This review will present the results of current epigenetic research using farm animal models (cattle, pigs, sheep and chickens). Much of the work has focused on the epigenetic effects that environmental exposures to toxicants, nutrients and infectious agents has on either the exposed animals themselves or on their direct offspring. Only one porcine study examined epigenetic transgenerational effects; namely the effect diet micronutrients fed to male pigs has on liver DNA methylation and muscle mass in grand-offspring (F2 generation). Healthy viable offspring are very important in the farm and husbandry industry and epigenetic differences can be associated with production traits. Therefore further epigenetic research into domestic animal health and how exposure to toxicants or nutritional changes affects future generations is imperative.
\end{abstract}

Keywords: Environment, Epigenetics, Pig, Review, Transgenerational

\section{Introduction}

Mendelian genetic theories have guided much of the biological research preformed in recent history. It has long been assumed that specific phenotypes arise only from DNA sequence. However, non-Mendelian inheritance patterns challenge these theories and suggest that an alternate process might exist to account for certain mechanisms of inheritance. Epigenetics provides a molecular mechanism that can account for these non-Mendelian observations [1-3]. Epigenetics research looks into modifications and inheritance patterns that do not involve changes in the DNA sequence, but do affect genome activity and gene expression [1-4]. There are four main mechanisms by which epigenetics can alter gene expression: DNA methylation, histone modification, chromatin structure, and non-coding RNA [1,5]. Although the epigenetic processes are highly conserved among all species, the specific epigenomes are highly divergent between species. Modifications of these epigenetic processes can occur due to direct environmental exposure at critical periods in the development of the organism

\footnotetext{
* Correspondence: skinner@wsu.edu

Center for Reproductive Biology, School of Biological Sciences, Washington State University, 99164-4236 Pullman, WA, USA
}

[1,6-8]. Clearly any generation that has direct exposure to an environmental insult may be altered in some way. Recent research shows subsequent generations that were not present at the time of the exposure can still be affected due to epigenetic transgenerational inheritance, if exposure occurred during sensitive developmental windows for the germ cells [9]. Epigenetic transgenerational inheritance is defined as germline-mediated inheritance of epigenetic information between generations, in the absence of direct environmental influences, that leads to phenotypic variation $[1,9]$. For example, if a pregnant animal is exposed to a toxicant during gonadal sex determination of the fetus then changes in fetal germ cell epigenetic programming may occur $[8,10]$. Therefore these offspring and the gametes that will form the grand-offspring are directly exposed to the toxicant, and changes seen in these F1 and F2 generations are not transgenerational [11]. However, epigenetic changes in the F3 generation (greatgrand-offspring) would be considered transgenerationally inherited. In contrast, if a male or non-pregnant female adult animal is subjected to an environmental exposure, then changes seen in the F2 generation or later are considered transgenerational [11]. Changes in DNA methylation in gametes that are transmitted to subsequent 
generations provide a mechanism for the inheritance of epigenetic information [12-14]. Non-coding RNA also appears to have a role in epigenetic transgenerational inheritance [15]. Much of the current research has used rodent models to demonstrate epigenetic changes after environmental insult, especially during pregnancy $[8,10]$. Germline epigenetic transgenerational inheritance has also been shown in plants, flies, worms, and humans [10,16-21].

Despite the amount of epigenetic and transgenerational epigenetic inheritance research being done on a multitude of mammal, insect, and plant models [8,10,16-21], a lack of research into these topics using farm animal models exists. This review will present the current epigenetic inheritance research and data using farm animal models (bovine, porcine, ovine, and gallus), Table 1. While much of the work has focused on the direct effects of environmental exposure to toxicants and nutrients, research into epigenetic transgenerational inheritance is limited. It is important that more epigenetic research be done in domesticated farm animals because of their close human relationships and potential for high pesticide exposure on farms. Pesticides have been shown to have dramatic transgenerational epigenetic effects on many animal models affecting the nervous system, reproductive and endocrine systems, and even causing cancer $[9,22]$. Since hybrid vigour (i.e. heterosis) has been shown to be critical in breeding of domestic animals, and epigenetics has a critical role in hybrid vigour [23], epigenetic inheritance will be important in developing optimal domestic animal breeds. Considering overpopulation issues requiring a rise in food supply, there may be more efficient ways of detecting and promoting favorable selection using epigenetics to breed for a lower instance of animal disease.

\section{Domestic animal models Bovine}

The relationship of DNA methylation and milk production in dairy cattle has been investigated. During lactation the bovine $\alpha \mathrm{S} 1$-casein gene is hypomethylated [24]. Research has characterized this gene during various physiological conditions during the lactation cycle. Vanselow et al. found that during lactation the (STAT)5-binding lactation enhancer, which is part of the $\alpha \mathrm{S} 1$-casein encoding gene, is hypomethylated [25]. However, during Escherichia coli infection of the mammary gland, this region becomes methylated at three $\mathrm{CpG}$ dinucleotides which accompanies a shut down of $\alpha \mathrm{S} 1$-casein synthesis [25]. These observations have also been shown with infection by Streptococcus uberis [26]. In addition, methylation of these same $3 \mathrm{CpG}$ dinucleotides has been seen during non-milking periods of healthy dairy cattle when milking was ceased suddenly [27]. González-Recio et al. preformed a generational study to see if a mother dairy cow affected the milk production of her offspring [28]. They found that female calves born to cows that were already lactating from previous births produced between 18 and $91 \mathrm{~kg}$ less milk in adulthood than calves that were first-born, and that their lifespans were also shorter [28]. Because of the generational effect, researchers suggested epigenetic inheritance. However, they did not look specifically at epigenetic differences in the affected calves versus controls.

More research has been done on histone modification related to nutritional changes than on DNA methylation. Short-chain fatty acids are particularly important in ruminant digestion, and are used for cell energy production and use [29]. Butyrate, a specific short-chain fatty acid, inhibits histone deacetylases which have been shown to regulate epigenetic changes to the genome [30]. Wu, et al. [31] show that high doses of butyrate exposure to Madin-Darby bovine kidney epithelial cells causes cell cycle arrest, changes in gene expression, changes in nucleic acid metabolic processes, regulation of the cell cycle, and changes in DNA replication. Therefore this study claims that histone acetylation is essential for diverse cellular processes [31], but histone acetylation was not measured directly.

The influence of epigenetics on disease has been studied in many animal models such as rats, mice, and humans, but very little has been done with cattle. One bovine developmental disease called large-offspring syndrome (LOS) has been found to have epigenetic components during embryonic growth. LOS has largely been associated with reproductive technologies commonly used with cattle such as in vitro fertilization and somatic-cell nuclear transfer [32]. Symptoms usually include increases in birth weight, organ overgrowth, difficulty breathing and standing, as well as skeletal and immunological defects. There are also increased rates of fetal and neonatal deaths [33-35]. Dean et al. [36] has reported methylation changes in bovine embryos (morulae) between controls, in vitro fertilized, and somatic-cell nuclear transfer embryos, and suggests that these methylation differences may account for the different success rates and health of calves born from these reproductive technologies [36]. A number of studies have demonstrated developmental epigenetic programming in bovine germ cells [37] and bovine embryos [38], which is similar among all mammalian species. In another study focusing on innate immunity, Green et al. [39] looked at epigenetics and individual variation in the innate immune response of bovine dermal fibroblasts, specifically via toll receptor signaling. Exposure to de-methylating and hyper-acetylating agents led to increased expression of several cytokines as compared to controls, suggesting immune gene expression has epigenetic regulation [39]. 
Table 1 Environmental epigenetics and epigenetic inheritance in domestic farm animals Environmental epigenetics and domestic farm animals

Bovine
Mammary gland-specific hypomethylation of Hpa II sites flanking the bovine
alpha S1-casein gene.
DNA-remethylation around a STAT5-binding enhancer in the alphaS1-casein
promoter is associated with abrupt shutdown of alphaS1-casein synthesis
during acute mastitis.
Transcriptome profiling of Streptococcus uberis-induced mastitis reveals fundamental
differences between immune gene expression in the mammary gland and in a
primary cell culture model.
Conservation of methylation reprogramming in mammalian development:
aberrant reprogramming in cloned embryos.
DNA methylation events associated with the suppression of milk protein gene
expression during involution of the bovine mammary gland.
Effect of maternal lactation during pregnancy
Large offspring syndrome in cattle and sheep.

The production of unusually large offspring following embryo manipulation: Concepts and challenges.

Postnatal characteristics of calves produced by nuclear transfer cloning.

Epigenetic contribution to individual variation in response to lipopolysaccharide in bovine dermal fibroblasts.

Occurrence, absorption and metabolism of short chain fatty acids in the digestive tract of mammals.

Butyrate induces profound changes in gene expression related to multiple signal pathways in bovine kidney epithelial cells.

Transcriptome Characterization by RNA-seq Unravels the Mechanisms of Butyrate-Induced Epigenomic Regulation in Bovine Cells.

In vitro produced and cloned embryos: Effects on pregnancy, parturition and offspring.

\section{Porcine}

Sulforaphane causes a major epigenetic repression of myostatin in porcine satellite cells.

Maternal dietary protein affects transcriptional regulation of myostatin gene distinctively at weaning and finishing stages in skeletal muscle of Meishan pigs.

HOX10 mRNA expression and promoter DNA methylation in female pig offspring after in utero estradiol-17beta exposure.

Investigations on transgenerational epigenetic response down the male line in F2 pigs.

Dietary Sulforaphane, a Histone Deacetylase Inhibitor for Cancer Prevention

Neonatal estradiol exposure alters uterine morphology and endometrial transcriptional activity in prepubertal gilts.

Maternal dietary protein restriction and excess affects offspring gene expression and methylation of non-SMC subunits of condensin I in liver and skeletal muscle.

Diet, methyl donors and DNA methylation: interactions between dietary folate, methionine and choline.

\section{Ovine}

Periconceptional nutrition and the early programming of a life of obesity or adversity.

The effect of maternal under-nutrition before muscle differentiation on the muscle fiber development of the newborn lamb.

Effect of maternal dietary restriction during pregnancy on lamb carcass characteristics and muscle fiber composition.

Context Ref.

Epigenetic regulation of lactation.

Epigenetic regulation of lactation.

Epigenetic regulation of lactation.

Epigenetic changes with assisted reproductive technologies

Epigenetic regulation of lactation.

Epigenetic regulation of lactation.

Epigenetic changes with assisted reproductive technologies

Epigenetic changes with assisted reproductive technologies

Epigenetic changes with assisted reproductive technologies

Epigenetic role in immunity

Epigenetic changes with regulation

of nutrition

Epigenetic changes with regulation of nutrition

Epigenetic changes with regulation of nutrition

Epigenetic changes with assisted reproductive technologies

Histone deacetylase inhibitor affects myostatin in vitro [41]

Maternal diet affects offspring epigenetics

Maternal steroid exposure affects offspring epigenetics

Paternal diet has transgenerational epigenetic effect

Epigenetic changes with regulation of nutrition

Steroid exposure affects epigenetics

Maternal diet affects offspring epigenetics

Epigenetic changes with regulation of nutrition

Maternal diet affects offspring epigenetics

Maternal diet affects offspring epigenetics

Maternal diet affects offspring epigenetics 


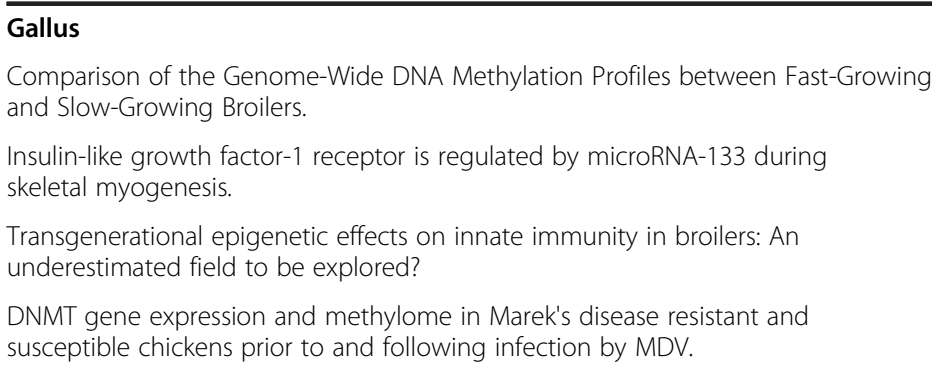

Epigenetic transgenerational inheritance study in domestic farm animals

Porcine
Differences in epigenetics between breeds

Epigenetic effects during muscle development

Review on role of epigenetics in innate immunity

Epigenetic role in immunity

Investigations on transgenerational epigenetic response down the male line in F2 pigs. Paternal diet has transgenerational epigenetic effect

No studies have been published showing epigenetic transgenerational inheritance in cattle.

\section{Porcine}

Swine are often used as animal models to study human disease because of the similar physiology between the two species. Because of this, much of the epigenetic porcine research involves exposure and response, with very little of the current research being transgenerational.

Epigenetic effects due to histone modification and acetylation have been studied in a porcine model both in order to increase meat production and to develop a potential treatment for muscular degenerative disease. Sulforaphane is a bioactive histone deacetylase inhibitor often found in edible vegetation like broccoli [40]. Fan et al. [41] treated porcine satellite cells with sulforaphane to epigenetically repress myostatin which would potentially result in more muscle growth [42]. Liu et al. [43] also looked at the myostatin pathway to investigate the short term and long term epigenetic changes in pigs based on maternal diet. These researchers concluded that histone modifications and changes in microRNA expression took place long term and played a part in skeletal muscle phenotype [43]. Another study looked at DNA methylation in response to altered protein and carbohydrate diets for maternal pigs during gestation [44]. Researchers found that hepatic global methylation was decreased in fetuses from protein-restricted mothers, likely caused by methionine deficiency [45]. However, skeletal muscle global methylation was not affected [44]. This study demonstrates maternal nutrition will likely have an epigenetic effect on embryonic tissue development. Epigenetic programming in the porcine germline has also been reported [46].

Research conducted by Tarletan et al. demonstrated that neonatal estrogen exposure in piglets can lead to epigenetic changes that affect uterine capacity and environment [47]. This leads to potentially less successful pregnancies once the piglets become adults [47]. Another environmental estrogen exposure experiment was preformed analyzing the effect on the gene HOXA10 by exposing offspring in utero to estradiol-17 $\beta$. No difference in HOXA10 expression was detected in either the low dose or high dose group [48]. However, differences in HOXA10 mRNA expression were detected between pre-pubescent and postpubescent gilts [48].

One recent transgenerational porcine study has been reported [49], Table 1. Braunschweig et al. preformed a three generational study to look at the effect of feeding on male epigenetic inheritance. The experimental group F0 generation males were fed a diet high in methylating micronutrients, and the resulting F2 generation had a lower fat percentage and higher shoulder muscle percentage as compared to controls. They also found significant differences in DNA methylation between the control and experimental groups, especially in the liver, which was proposed to epigenetically affect fat metabolism pathways [49].

\section{Ovine}

As shown in the bovine model and porcine model, maternal nutritional impact is a common topic in epigenetic research, and ovine studies are no exception. Zhang et al. [50] looked into the effects of maternal over-nutrition in sheep, both during peri-conception and during the late stages of pregnancy. They found that over-nutrition in late stages of pregnancy resulted in more visceral fat in offspring and a change in appetite that pre-disposed that lamb to over-eat in adult life. More interestingly, they also found that over-nutrition at the peri-conception period led to higher rates of visceral fat in only female ewe offspring, leading to a conclusion of sex-specific DNA methylation. They also found that when diet was restricted just before conception (maternal under-nutrition), the adrenal glands of the offspring tended to be heavier and have less methylation of the IGF2/H19 differentially methylated regions in the adrenal. Observations suggested that while a restricted peri-conception diet led to no maternal epigenetic influence on bodyweight, it did 
increase the stress response in these offspring [50]. Other nutritional studies have looked at muscle development in response to maternal under-nutrition during pregnancy and have shown that maternal under-nutrition causes a decrease of fast muscle fibers in early stages, but an increase in them during later stages of development $[51,52]$. However, these studies did not investigate epigenetic mechanisms.

No studies have been published showing epigenetic transgenerational inheritance in sheep.

\section{Gallus}

Marek's disease in chickens is a manifestation of Marek's disease virus and progresses to become a T-cell lymphoma that affects chickens and other birds. Vaccines have been developed but they are not completely successful [53]. Tian et al. [54] set to find out why one breeding line seemed resistant to the virus, while another was more susceptible. They found that in the virus-resistant line, DNA methylation levels in thymus cells were decreased after exposure to the virus. They also found that with pharmacological inhibition of DNA methylation in vitro the propagation in the infected cells was slowed. Observations suggested that DNA methylation in the host may be associated with virus resistance or susceptibility [54].

Different developmental epigenetic patterns have been studied between chicken types. One study looked at differential DNA methylation in breast muscle between slow-growing and fast-growing broiler chickens [55]. They found that between the two breeds of chickens there were 75 differentially methylated genes, including several genes belonging to the fibroblast growth factor (FGF) family. The FGF family is known for its role in many growth processes [56]. In addition, effects in the insulin growth factor receptor (IGF1R) were observed that influence skeletal muscle growth specifically $[57,58]$.

As one review indicated, many poultry studies indicate that there may be epigenetic effects, and even transgenerational epigenetic inheritance, though very few studies actually test for DNA methylation or histone modification in their research [59].

No studies have been published showing epigenetic transgenerational inheritance in chicken.

\section{Conclusion}

While a good amount of epigenetic research has been preformed on domesticated farm animals still more needs to be done, Table 1 . There is little research at all in transgenerational inheritance of these epigenetic modifications. This could be due to the fact that farm animals are more difficult and more costly to raise than other common animal research models. In addition, they have longer lifespans so transgenerational studies take more time and resources. Animal science researchers should cultivate an interest in conducting these types of experiments for a number of reasons. Healthy viable offspring are very important in the farm and husbandry industry and epigenetic differences can be associated with production traits. Recently there has been a lot of social pressure to cut down on vaccination and antibiotic use for animals raised for meat and epigenetics research may help to provide the key to lowering disease and increasing immunity. Therefore research into domestic animal health and how exposure to toxicants such as pesticides affects future generations is imperative.

\section{Glossary}

Epigenetics: Molecular factors/processes around the DNA that regulate genome activity independent of DNA sequence, and are mitotically stable.

Epigenetic: Transgenerational Inheritance: Germlinemediated inheritance of epigenetic information between generations in the absence of direct environmental influences, that leads to phenotypic variation.

Epimutation: Differential presence of epigenetic marks that lead to altered genome activity.

\section{Abbreviations}

F0: Generation pregnant female; F1: Generation fetus that becomes the offspring or children; F2: Generation (grandchildren); F3: Generation (greatgrandchildren); LOS: Large-offspring syndrome; FGF: Fibroblast growth factor; IGF1R: Insulin growth factor receptor.

\section{Competing interests}

The authors declare that they have no competing interests.

\section{Authors' contributions}

All authors designed and wrote the study. All authors edited and approved the manuscript.

\section{Acknowledgements}

We acknowledge the assistance of Ms. Heather Johnson for assistance in preparation of the manuscript. The current address for Ms. Amanda Feeney is New York Medical College- Valhalla, New York. This research was

supported by NIH grants to MKS.

Received: 28 July 2014 Accepted: 14 October 2014

Published: 23 October 2014

\section{References}

1. Skinner MK, Manikkam M, Guerrero-Bosagna C: Epigenetic transgenerational actions of environmental factors in disease etiology. Trends Endocrinol Metab 2010, 21:214-222.

2. Jirtle RL, Skinner MK: Environmental epigenomics and disease susceptibility. Nat Rev Genet 2007, 8:253-262.

3. Guerrero-Bosagna C, Skinner MK: Environmentally induced epigenetic transgenerational inheritance of phenotype and disease. Mol Cell Endocrinol 2012, 354:3-8.

4. Simmons D: Epigenetic influence and disease. Nat Educ 2008, 1:6.

5. Egger G, Liang G, Aparicio A, Jones PA: Epigenetics in human disease and prospects for epigenetic therapy. Nature 2004, 429:457-463.

6. Vandegehuchte MB, Janssen CR: Epigenetics in an ecotoxicological context. Mutat Res Genet Toxicol Environ Mutagen 2014, 764-765:36-45.

7. Baccarelli A, Bollati V: Epigenetics and environmental chemicals. Curr Opin Pediatr 2009, 21:243-251

8. Anway MD, Cupp AS, Uzumcu M, Skinner MK: Epigenetic transgenerational actions of endocrine disruptors and male fertility. Science 2005 , 308:1466-1469. 
9. Skinner MK: Environmental epigenetic transgenerational inheritance and somatic epigenetic mitotic stability. Epigenetics 2011, 6:838-842.

10. Manikkam M, Guerrero-Bosagna C, Tracey R, Haque MM, Skinner MK: Transgenerational actions of environmental compounds on reproductive disease and identification of epigenetic biomarkers of ancestral exposures. PLoS One 2012, 7:e31901.

11. Skinner MK: What is an epigenetic transgenerational phenotype? F3 or F2. Reprod Toxicol 2008, 25:2-6.

12. Lees-Murdock DJ, Walsh CP: DNA methylation reprogramming in the germ line. Epigenetics 2008, 3:5-13.

13. Reik W, Dean W, Walter J: Epigenetic reprogramming in mammalian development. Science 2001, 293:1089-1093.

14. Smith ZD, Chan MM, Mikkelsen TS, Gu H, Gnirke A, Regev A, Meissner A: $A$ unique regulatory phase of DNA methylation in the early mammalian embryo. Nature 2012, 484:339-344.

15. Gapp K, Jawaid A, Sarkies P, Bohacek J, Pelczar P, Prados J, Farinelli L, Miska E, Mansuy IM: Implication of sperm RNAs in transgenerational inheritance of the effects of early trauma in mice. Nat Neurosci 2014, 17:667-669.

16. Guerrero-Bosagna C, Settles M, Lucker B, Skinner M: Epigenetic transgenerational actions of vinclozolin on promoter regions of the sperm epigenome. PLoS One 2010, 5:e13100.

17. Arico JK, Katz DJ, van der Vlag J, Kelly WG: Epigenetic patterns maintained in early Caenorhabditis elegans embryos can be established by gene activity in the parental germ cells. PLoS Genet 2011, 7:e1001391.

18. Carone BR, Fauquier L, Habib N, Shea JM, Hart CE, Li R, Bock C, Li C, Gu H, Zamore PD, Meissner A, Weng Z, Hofmann HA, Friedman N, Rando OJ: Paternally induced transgenerational environmental reprogramming of metabolic gene expression in mammals. Cell 2010, 143:1084-1096.

19. Dunn GA, Bale TL: Maternal high-fat diet effects on third-generation female body size via the paternal lineage. Endocrinology 2011, 152:2228-2236.

20. Morgan CP, Bale TL: Early prenatal stress epigenetically programs dysmasculinization in second-generation offspring via the paternal lineage. J Neurosci 2011, 31:11748-11755.

21. Saze $H$ : Transgenerational inheritance of induced changes in the epigenetic state of chromatin in plants. Genes Genet Syst 2012, 87:145-152.

22. Collotta M, Bertazzi PA, Bollati V: Epigenetics and pesticides. Toxicology 2013, 307:35-41.

23. Groszmann M, Greaves IK, Fujimoto R, Peacock WJ, Dennis ES: The role of epigenetics in hybrid vigour. Trends Genet 2013, 29:684-690.

24. Platenburg GJ, Vollebregt EJ, Karatzas CN, Kootwijk EP, De Boer HA, Strijker $\mathrm{R}$ : Mammary gland-specific hypomethylation of $\mathrm{Hpa}$ II sites flanking the bovine alpha S1-casein gene. Transgenic Res 1996, 5:421-431.

25. Vanselow J, Yang W, Herrmann J, Zerbe H, Schuberth HJ, Petzl W, Tomek W, Seyfert HM: DNA-remethylation around a STAT5-binding enhancer in the alphaS1-casein promoter is associated with abrupt shutdown of alphaS1-casein synthesis during acute mastitis. J Mol Endocrinol 2006, 37:463-477.

26. Swanson KM, Stelwagen K, Dobson J, Henderson HV, Davis SR, Farr VC, Singh K: Transcriptome profiling of Streptococcus uberis-induced mastitis reveals fundamental differences between immune gene expression in the mammary gland and in a primary cell culture model. J Dairy Sci 2009, 92:117-129.

27. Singh K, Swanson K, Couldrey C, Seyfert H-M, Stelwagen K: DNA methylation events associated with the suppression of milk protein gene expression during involution of the bovine mammary gland. Proc N Z Soc Anim Prod 2009, 69:57-59.

28. González-Recio O, Ugarte E, Bach A: Trans-generational effect of maternal lactation during pregnancy: a Holstein cow model. PLoS One 2012, 7(12):e51816.

29. Bugaut M: Occurrence, absorption and metabolism of short chain fatty acids in the digestive tract of mammals. Comp Biochem Physiol B 1987, 86:439-472.

30. Li RW, Li C: Butyrate induces profound changes in gene expression related to multiple signal pathways in bovine kidney epithelial cells. BMC Genomics 2006, 7:234.

31. Wu S, Li RW, Li W, Li CJ: Transcriptome characterization by RNA-seq unravels the mechanisms of butyrate-induced epigenomic regulation in bovine cells. PLoS One 2012, 7:e36940

32. Kruip TAM, den Daas JHG: In vitro produced and cloned embryos: effects on pregnancy, parturition and offspring. Theriogenology 1997, 47:43-52.
33. Young LE, Sinclair KD, Wilmut I: Large offspring syndrome in cattle and sheep. Rev Reprod 1998, 3:155-163.

34. Walker SK, Hartwich KM, Seamark RF: The production of unusually large offspring following embryo manipulation: concepts and challenges. Theriogenology 1996, 45:111-120.

35. Garry FB, Adams R, McCann JP, Odde KG: Postnatal characteristics of calves produced by nuclear transfer cloning. Theriogenology 1996, 45:141-152.

36. Dean W, Santos F, Stojkovic M, Zakhartchenko V, Walter J, Wolf E, Reik W: Conservation of methylation reprogramming in mammalian development: aberrant reprogramming in cloned embryos. Proc Natl Acad Sci U S A 2001, 98:13734-13738.

37. Heinzmann J, Hansmann T, Herrmann D, Wrenzycki C, Zechner U, Haaf T, Niemann $\mathrm{H}$ : Epigenetic profile of developmentally important genes in bovine oocytes. Mol Reprod Dev 2011, 78:188-201.

38. Niemann H, Carnwath JW, Herrmann D, Wieczorek G, Lemme E, Lucas-Hahn A, Olek S: DNA methylation patterns reflect epigenetic reprogramming in bovine embryos. Cell Reprogram 2010, 12:33-42.

39. Green BB, Kerr DE: Epigenetic contribution to individual variation in response to lipopolysaccharide in bovine dermal fibroblasts. Vet Immunol Immunopathol 2014, 157:49-58.

40. Ho E, Clarke JD, Dashwood RH: Dietary sulforaphane, a histone deacetylase inhibitor for cancer prevention. J Nutr 2009, 139:2393-2396.

41. Fan H, Zhang R, Tesfaye D, Tholen E, Looft C, Holker M, Schellander K, Cinar $\mathrm{MU}$ : Sulforaphane causes a major epigenetic repression of myostatin in porcine satellite cells. Epigenetics 2012, 7:1379-1390.

42. Benny Klimek ME, Aydogdu T, Link MJ, Pons M, Koniaris LG, Zimmers TA: Acute inhibition of myostatin-family proteins preserves skeletal muscle in mouse models of cancer cachexia. Biochem Biophys Res Commun 2010, 391:1548-1554.

43. Liu X, Wang J, Li R, Yang X, Sun Q, Albrecht E, Zhao R: Maternal dietary protein affects transcriptional regulation of myostatin gene distinctively at weaning and finishing stages in skeletal muscle of Meishan pigs. Epigenetics 2011, 6:899-907.

44. Altmann S, Murani E, Schwerin M, Metges CC, Wimmers K, Ponsuksili S: Maternal dietary protein restriction and excess affects offspring gene expression and methylation of non-SMC subunits of condensin I in liver and skeletal muscle. Epigenetics 2012, 7:239-252.

45. Niculescu MD, Zeisel SH: Diet, methyl donors and DNA methylation: interactions between dietary folate, methionine and choline. J Nutr 2002, 132:2333S-2335S

46. Hyldig SM, Croxall N, Contreras DA, Thomsen PD, Alberio R: Epigenetic reprogramming in the porcine germ line. BMC Dev Biol 2011, 11:11.

47. Tarleton BJ, Wiley AA, Bartol FF: Neonatal estradiol exposure alters uterine morphology and endometrial transcriptional activity in prepubertal gilts. Domest Anim Endocrinol 2001, 21:111-125.

48. Pistek VL, Furst RW, Kliem H, Bauersachs S, Meyer HH, Ulbrich SE: HOXA10 mRNA expression and promoter DNA methylation in female pig offspring after in utero estradiol-17beta exposure. J Steroid Biochem Mol Biol 2013, 138:435-444

49. Braunschweig M, Jagannathan V, Gutzwiller A, Bee G: Investigations on transgenerational epigenetic response down the male line in $\mathrm{F} 2$ pigs. PLoS One 2012, 7:e30583.

50. Zhang S, Rattanatray L, McMillen IC, Suter CM, Morrison JL: Periconceptional nutrition and the early programming of a life of obesity or adversity. Prog Biophys Mol Biol 2011, 106:307-314.

51. Fahey AJ, Brameld JM, Parr T, Buttery PJ: The effect of maternal undernutrition before muscle differentiation on the muscle fiber development of the newborn lamb. J Anim Sci 2005, 83:2564-2571.

52. Daniel ZC, Brameld JM, Craigon J, Scollan ND, Buttery PJ: Effect of maternal dietary restriction during pregnancy on lamb carcass characteristics and muscle fiber composition. J Anim Sci 2007, 85:1565-1576.

53. Davison F, Nair V: Marek's Disease: An Evolving Problem. London: Elsevier Science Press; 2004.

54. Tian F, Zhan F, Vanderkraats ND, Hiken JF, Edwards JR, Zhang H, Zhao K, Song J: DNMT gene expression and methylome in Marek's disease resistant and susceptible chickens prior to and following infection by MDV. Epigenetics 2013, 8(4):431-444.

55. Hu Y, Xu H, Li Z, Zheng X, Jia X, Nie Q, Zhang X: Comparison of the genome-wide DNA methylation profiles between fast-growing and slow-growing broilers. PLOS One 2013, 8:e56411. 
56. Itoh N: The Fgf families in humans, mice, and zebrafish: their evolutional processes and roles in development, metabolism, and disease. Biol Pharm Bull 2007, 30:1819-1825.

57. Liu JP, Baker J, Perkins AS, Robertson EJ, Efstratiadis A: Mice carrying null mutations of the genes encoding insulin-like growth factor I (Igf-1) and type 1 IGF receptor (Igf1r). Cell 1993, 75:59-72.

58. Huang MB, Xu H, Xie SJ, Zhou H, Qu LH: Insulin-like growth factor-1 receptor is regulated by microRNA-133 during skeletal myogenesis. PLoS One 2011, 6:e29173.

59. Berghof TV, Parmentier HK, Lammers A: Transgenerational epigenetic effects on innate immunity in broilers: an underestimated field to be explored? Poult Sci 2013, 92:2904-2913.

doi:10.1186/2049-1891-5-48

Cite this article as: Feeney et al: Epigenetics and transgenerational

inheritance in domesticated farm animals. Journal of Animal Science and Biotechnology 2014 5:48.

\section{Submit your next manuscript to BioMed Central and take full advantage of:}

- Convenient online submission

- Thorough peer review

- No space constraints or color figure charges

- Immediate publication on acceptance

- Inclusion in PubMed, CAS, Scopus and Google Scholar

- Research which is freely available for redistribution 